\title{
Simplified Modeling and Solving of Logistics Optimization Problems
}

\author{
Hanno Friedrich ${ }^{1}$ and Jonathan Gumpp ${ }^{2}$ \\ ${ }^{1}$ Institut für Verkehr (IfV) - Juniorprofessur Wirtschaftsverkehr \\ Technical University of Darmstadt Petersenstraße 30, 64287 Darmstadt, Germany \\ ${ }^{2}$ Institut für Verkehr (IfV) - Juniorprofessur Wirtschaftsverkehr \\ Technical University of Darmstadt Petersenstraße 30, 64287 Darmstadt, Germany \\ ${ }^{1}$ friedrich@verkehr.tu-darmstadt.de, ${ }^{2}$ j.gumpp@web.de
}

\begin{abstract}
Logistics optimization problems are often complex (NP-hard). Especially for large problem scopes in logistics and new agent-based freight transport models which have to solve these problems for many agents, simplifying modeling and solving procedures are necessary in order to reduce the level of complexity. Due to the variety of existing approaches and the specifics of each problem it is often difficult to find an appropriate method. This paper seeks to facilitate this process as it identifies 'meta' heuristics within literature, i.e. abstract courses of action that, when adapted, have proven successful in various problems. It presents a classification of general simplification principles that are useful for reducing the complexity of logistics problems, in order to facilitate understanding between academics and practice. The derivation of the related principles is based on the examination of five problems in logistics literature: facility location, distribution system, lot size, bin packing, and vehicle routing.
\end{abstract}

Keywords: Simplified logistics modeling, approximation, (meta) heuristics, operations research, transportation research

\section{Introduction}

Major differences between the theory and practice of logistics optimization suggest the differentiation of two independent fields: academics, on the one hand, works on complex modeling and solution approaches which represent reality in more and more detail; business, on the other hand, works with simple methods that are operable in practice. It is almost contradictory: the former encounters the accusation of ivory-tower activity (i.e., removed from reality) through increasing complexity and variety of their work - e.g., Eksioglu, et al., [33] identify an exponential growth of vehicle-routing literature over the past decades, and a tendency to computationally intensive cases. The latter simplifies its (operative) problems considerably in order to render them solvable via 'manual optimization', i.e., based on human experience - while only problems of extensive range may be handled academically (using simulation, consultants, etc.,). The work of Friedrich [38] or Fuchsenberger [39] in the area of transportation science supports this theory. Comparing, for example, procedures in the context of lot-size disposition, different approaches in regard to restrictions can be observed. Instead of an immediate consideration of constraints, resulting in the compliance of the proposed lot size, as it is done in theory, in practice the proposition is first developed, and then (if at all) its validity is proven - due to greater solution liberty, computational complexity lessens. Please also note [70] regarding the gap between theory and practice in inventory 
control. The insight of the authors in the area of automotive logistics confirms a deviation between academic theory and operative instruments as well.

Therefore, the aim of research should be the development of conceptually simple yet qualitatively sound, i.e., feasible methods. Complexity mitigation need not be a disadvantage. Solutions of exact procedures are often not robust, lacking "insensitivity [...] towards [...] environmental influences" ([94], p. 91). In other words, small changes of the input parameter can result in large changes of the output parameter. Due to uncertainties that are almost inevitably part of reality due to imperfect information, exactness can even have negative effects - model solution and real characteristics might deviate considerably. See, e.g., [22] for an examination of the correlation between model precision and solution accuracy.

In recent years, transport modelers have attempted to incorporate more and more logistics details into freight transport models; most of these developments are described and analyzed in a number of overview papers $([12,26,106])$. For these models as well, it is important to incorporate logistics solution procedures that have a limited complexity in theory but represent best decisions in reality. Therefore, this work dares to take a step backwards. Its aim is the identification of a framework that yields an overview of principles of simplification - as a bridge between science and practice. This can serve practitioners as well as transportation modelers. The aim is not the formulation of a new theory, but rather the consideration of existing as the foundation of a continued examination. The innovation lies in the extraction and classification of modeling and solution procedures identified in literature, or rather their underlying approaches. A clarification is given through a short description of related examples.

This paper is organized as follows: Chapter 2 gives a short introduction to model theory, optimization and its instruments - the underlying material that is fundamental knowledge when identifying simplification principles. Chapter 3 derives the importance of the logistics problems that have been the subject of the analysis on which this classification is based facility location, distribution system, lot sizing, bin packing and vehicle routing. The classification, its principles and its mechanisms are then presented and exemplified in Chapter 4. Finally, we summarize the results (Chapter 5).

\section{Modeling and Optimization}

A model is, generally defined on the basis of [107] (p. 8), "a simplified mapping, created for a certain objective, of a detail of reality perceived as a system". It is necessary as the original requires a reduction or expansion to be descriptive, the original is not accessible, or the original is too complex in its variety of characteristics to explain its inner interrelations or to predict its behavior ([104], p. 139). This definition contains the three following fundamental properties that are part of every model - see [107] (p. 8f.):

* Mapping: Models are representations of originals (which may be models themselves). Model and original are in an analogy relation, i.e. their attributes are assigned to one another, allowing a purposeful and conclusive system correlation.

* Reduction: Models do not capture all the attributes of the original, only those attributes that are of interest to the user. The relevance of characteristics is determined by the model's objective.

* Pragmatism: The model-original relation is determined by an objective, i.e. it is not a natural or general assignment. Models serve as substitutes for the original for a 
limited time, serve certain persons for certain purposes and are restricted to certain operations.

The modeling or mapping is therefore a first opportunity for problem simplification since it includes selection and transfer - diminishing complexity. It is nonetheless due to complexity that in many cases a model's optimal solution is unreachable, as the knowledge of the (global) optimum depends on the knowledge of the entire solution space, and can therefore frequently not be determined efficiently; e.g., the combinatorial problem of the traveling salesman with $n$ cities yields $n$ ! solutions. Hence, optimization must be based on the premise of maintainable effort - the objective must be a solution that suffices ([100], p. 119). Essentially, problems may have to be reduced furthermore. The consideration of logistics problems undertaken in this work is based on mathematical modeling, a mapping of reality (object) to mathematics (model). The derivation of an objective insight relies on the conversion of input to output. Besides the model itself, algorithms, as the method of examination, play an essential role in the context of the optimization.

Cormen, et al., [18] (p. 5) describe an algorithm as "any well-defined computational procedure that takes some value, or set of values, as input and produces some value, or set of values, as output", and is thus "a sequence of computational steps that transform the input into output". One differentiates between algorithms according to their tractability, i.e. their worst-case running time: either it is equal to or larger than $\mathcal{O}\left(n^{k}\right)$, for some constant $k$ and input size $n$, solving problems of class $\mathrm{P}$ in polynomial time or problems of class NPcomplete in superpolynomial time ([18], p. 966f.). Since polynomial time is an essential requirement for computability, for a variety of logistics problems (e.g., the vehicle routing problem or the bin packing problem) belonging to NP-complete and having exponential growth, an efficient generation of an optimal solution is unknown (for a formal definition see [18] (Ch. 34)). Nevertheless, approximation makes it possible to approach optimization. What is the difference?

Optimization deals with the determination of the admissible course of action which is best, according to an objective ([111], p. 8). Its execution does not necessarily yield a (globally) optimal solution. One can differentiate between four solution methods:

* Complete enumeration means the consideration and evaluation of all alternatives, among them the optimal choice. This is only advisable in the case of a small input size.

* Exact algorithms do not completely enumerate yet still compute the optimal solution of an optimization problem. Due to the polynomial time restriction, they are not always applicable.

- Approximation algorithms are efficient procedures that a) always give a feasible solution, b) in polynomial time and c) of a certain assured quality level. Often they are characterized by an $\alpha$, meaning the algorithm's solution is "at most $\alpha$ times the optimum" ([45], p.558).

* Metaheuristics ${ }^{1}$ heuristics offer no guarantee that an optimal solution will be found or identified as such. They embrace "certain courses of action for solution finding or

\footnotetext{
${ }^{1}$ The authors differentiate between two meanings of metaheuristics: a) Metaheuristics, generally defined, are "principles of procedure" providing an abstract framework that needs further adaption/ clarification but which has
} 
improvement" that are "reasonable, appropriate, and promising" in regard to the objective and the problem structure. While metaheuristics are based on a general approach which is easily adaptable to a specific problem, heuristics are usually formulated problem-specifically ([30], p. 21).

For further information regarding the derivation and design of algorithms/ heuristics in general, see [82] and [81]. This paper considers neither complete enumeration nor exact algorithms - only approximation algorithms and heuristics, as they are able to solve NP-hard problems like those present.

Taking a closer look, e.g. into heuristics, one can distinguish a variety of concepts. Gomes and Williams [45] give a rather coarse division, stating three strategies of heuristics: greedy, sequential, and random. More elaborate, Domschke and Scholl [30] (p. 21ff.) classify the set of heuristic procedures as follows: opening, local search/ improvement, population-based, incompletely executed exact, and relaxation-based. Further, even more detailed classifications can be found in Silver [98]; Silver, et al. [99]; Ball and Magazine [5]; or Zanakis, et al. [113]. This diversity is based on different approaches regarding proceeding and application, exhibiting different levels of solution quality and complexity of solving.

Thus, not only the modeling, i.e. the mapping of a problem serves as means of reduction, but also the algorithmic solution procedure.

\section{Logistics Problems}

As the motivation of this work is based on interests in the field of transportation science, it seems necessary to take a look at the fundamentals of freight-transport demand modeling in order to identify the logistics problems involved. The starting point shall be a reduced version of Friedrich's [38] (p. 20) presentation of a freight triggering decision hierarchy, specifying the levels of choice from the perspective of a company. A rough differentiation into two categories is possible:

1. Constituting economic decisions that determine the essence of business activity: the company's strategic orientation (aspiration), its business proposal and operation method (activity pattern), and its chosen region of activity (business location).

2. Logistic choices of tactical/ operative orientation: The assignment of logistics locations (warehouses, reloading points) builds connections between sourcing, production, and retail. The supply path describes the assignment of commodity flows within this network. Thus, the tactically optimal way of transportation is determined. The supply modalities describe the means of transportation, the options that are offered. The transportation mode (flight, road, etc.), the quality of delivery (just in sequence, temperature, express, etc.) or the frequency can be specifications. Dispatching signifies the actual execution of the transportation, the operatively optimal realization. Questions concerning tour or lot size are typical for this stage.

The following five planning classes (and the forms related to them) are embedded within this hierarchy - in the given order:

proven to be a promising solution approach on a meta level in various instances - see e.g. [30], p. 21. Their identification and reflection is the aim of this work. But, b) in literature the word metaheuristics is closely related or almost synonymously used for heuristics like simulated annealing, genetic algorithms, tabu search, etc., building an own branch of research now. This more narrow understanding of metaheuristics is meant here. 
2.1 Facility location seeks to determine the according to an objective optimal geographic place of a set of facilities serving a set of demand points with respect to some constraints. Only operative and normative models with a focus on cost-minimal allocation have been examined. Typical examples are the p-median or the covering location problem.

2.2 Distribution system signifies the simultaneous optimization of multiple echelons regarding location and allocation in an environment of demand points; furthermore, it includes approaches of an integrated treatment of all participants, considering "procurement, production, inventory, distribution, and routing", according to [76] (p. 401). Models are usually labeled "production distribution", "inventory distribution", "supply chain", or "multi-echelon inventory".

2.3 Lot size describes the determination of the optimal replenishment strategy - usually balancing between fixed order costs (decreasing with amount) and variable inventory costs (proportional to amount). Variables which influence order size are usually demand and lead time. Therefore, the question of inventory policy is closely related. The models are often referred to as inventory problems in literature.

2.4 Bin packing is concerned with the creation of an optimal packing within a container. Due to capacitive restrictions in transportation and storage, as efficient a use of space as possible is required in order to secure minimum costs through the minimal number of containers. The knapsack problem, which considers multiple dimensions per item (often weight and value) is closely related to the bin-packing problem.

2.5 Vehicle routing strives for an optimal allocation (space and time) of assignments to vehicles under certain objectives (costs, service level, etc.) and constraints. Its execution is characterized by two steps: the tours - the division of the customer set into subsets - and the routes - the order in which the customers are served. Wellknown (and well-researched) is the vehicle routing problem with its wide variety of characteristics as well as the 'notorious' traveling salesman problem.

For further information regarding these five problems please refer to the sources given in Table 1. 
Table 1. Continuative Sources On Logistic Problems

\begin{tabular}{|l|l|}
\hline Type & Sources \\
\hline Facility location & $\begin{array}{l}\text { Klose and Drexl [63] give a very good introduction in facility location } \\
\text { models (types, applications, etc.). For a more in-depth study (e.g. Ch. 1deals } \\
\text { only with distance functions) see Farahani and Hekmatfar [36]. }\end{array}$ \\
\hline Distribution system & $\begin{array}{l}\text { Very interesting overview paper on facility locating in supply chains by } \\
\text { Melo, et al. [76] with various typologies. }\end{array}$ \\
\hline Lot size & $\begin{array}{l}\text { General overview by Drexl and Kimms [31]. Characteristics and variants of } \\
\text { single-level lot sizing are given by Karimi, et al. [60]. For developments } \\
\text { over time (single-item lot size) consult Wolsey [111]. }\end{array}$ \\
\hline Bin packing & $\begin{array}{l}\text { Models/ solutions of 2-/3-dimensional packing problems, compiled by } \\
\text { Downsland and Downsland [27] }\end{array}$ \\
\hline Vehicle routing & $\begin{array}{l}\text { Extensive taxonomy of Eksioglu, et al. [33]. "50 years of vehicle routing”, a } \\
\text { recent account of developments by Laporte [68]. }\end{array}$ \\
\hline
\end{tabular}

The examination of these classes represents the entire logistics planning process. These five problems, their models and solution procedures have been the starting point for the considerations that led to the classification of simplification principles explained in the next section.

\section{Principles of Simplification}

The aim of this paper is the identification and description of application approaches; in the following section, their classification (Figure 1) is outlined further. The principles intervene, as indicated, at two points of action: the model and/ or the heuristics. Thus, the classification consists of three classes linked to these that offer potential for simplification (from a point of view of an unspecified solution procedure) - the model input, the solution procedure itself, and the model output:

* Model input, i.e., what characterizes the data base? This category primarily arises from modeling itself - the model as an input parameter for the solution procedure. The degree of abstraction as input for the problem size - a major source of complexity - plays an important role.

* Solution procedure, i.e., which actions are undertaken by the solution approach? The transformation of input parameter to output parameter is at the heart of the heuristic examination of optimization problems. Although it builds on the input parameter, it has a huge potential for simplification. Its course of action substantially determines computation effort and solution quality.

* Model output, i.e., what defines the result? The result represents the solution method, and is therefore closely linked to it. The principles contained are (partially) based on particular procedures - and thus exhibit a close link to the previous category. However, they are examined independently as they are most strongly characterized by their result.

For the depiction of the classification, please note Figure 1. In the following the principles are further outlined. After each section a table on related sources is provided, giving further exemplifications as well as 'hints' on where to start or continue a specific search. Due to the often high variety of (sub)approaches within each principle, this listing falls far short, yet we 
sought to give interesting examples that tend to be in some way general or basic in order to support the access into a topic. As the principles are not mutually exclusive, the consideration of other approaches might be worthwhile.

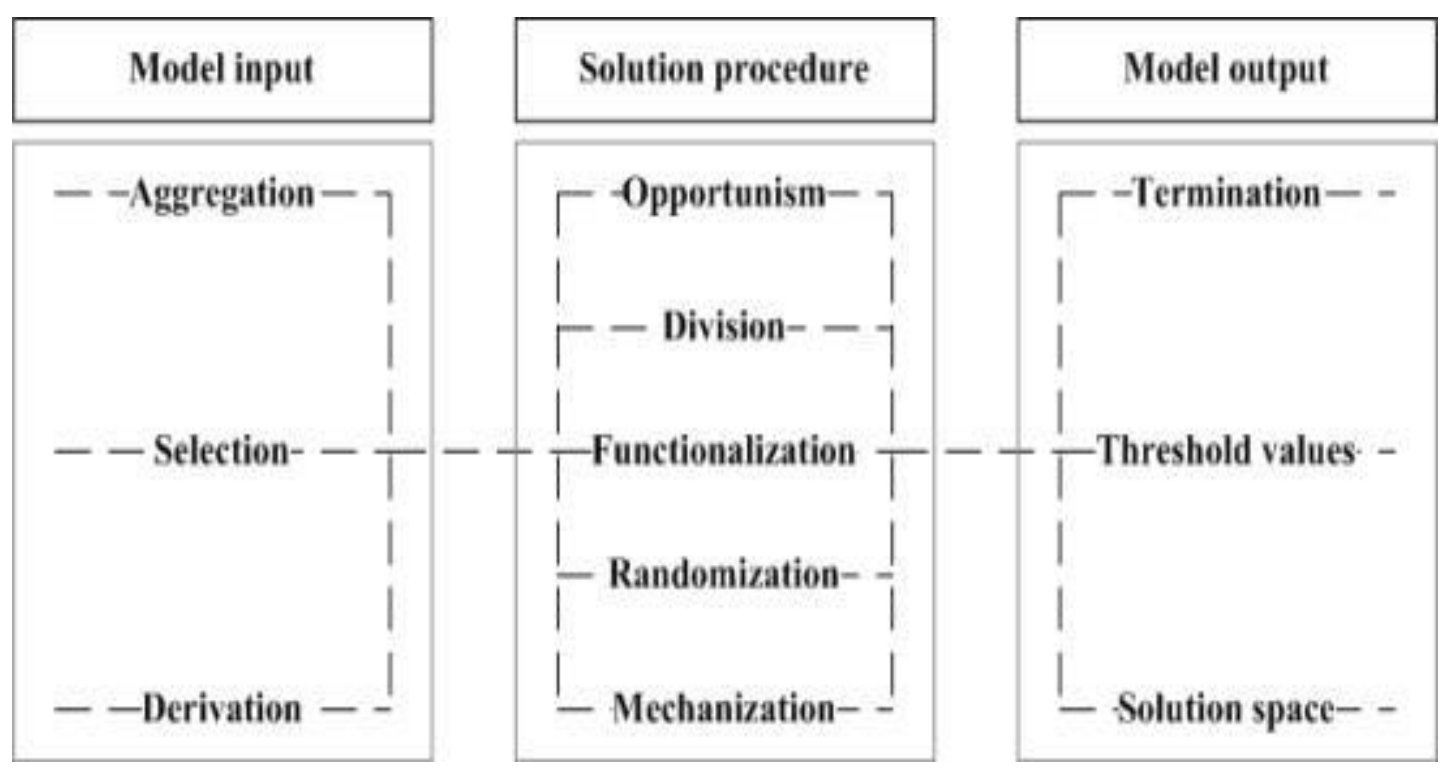

Figure 1. Classification of Simplification Principles

Aggregation denotes the decrease in the level of detail of data under loss of information e.g., the clustering of customer demands. The abstracting treatment results in an "auxiliary" model of reduced "input size and/ or complexity" ([90]). Consideration of the aggregation error is essential for validity, ensuring the appropriate equilibrium between computing effort and solution quality. Entities which are to be aggregated, be they "variables, constraints, or both", should be chosen according to the desired goal - e.g., error minimization or ease of approximation ([90], p. 556). Clustering then seeks to match entities that are similar to each other in sets that are dissimilar to each other - in case no "natural partitioning [...] is apparent" (e.g., through vicinity), or no specifics are given, the use of cluster analysis (a science in and of itself, with its own algorithms - see e.g., [62]) is suggested ([96], p. 386). Error bounds support the evaluation/ selection of different approaches: a priori and a posteriori, i.e., determined before or after solving the aggregate model - the latter being tighter due to more information, according to [87]. Finally, disaggregation techniques may seek to retranslate the reduced model's outcome to the original model's solution.

Example: Andersson, et al., [2] simplify a p-median problem through demand-point aggregation, replacing e customers with $q \ll e$ representatives: In a first strategy step the network is partitioned using a grid with column-row-width determined by solving a onedimensional c-median and r-median problem on the $\mathrm{x}$-axis and $\mathrm{y}$-axis projection of the sinks. The tactics step determines an aggregate demand point within each subnetwork, a network 1median problem, resulting in $q \leq \mathrm{cr} \ll e$ aggregators (depending on the existence of demand within each grid element). The outcome is the input for the subsequently solved p-median problem. The authors exemplify their approach on the basis of U.S. census data, e.g. Jacksonville with $e=200.000, p=5$ and a sample maximum relative error of at most $1 \%$ for $q \geq 500$. 
Table 2. Continuative Sources on Aggregation

\begin{tabular}{|l|l|}
\hline Type & Sources \\
\hline General & $\begin{array}{l}\text { Roger, et al. [90] introduce a general framework on aggregation/ } \\
\text { disaggregation in optimization. For specialists: Livinchevs [70] book. }\end{array}$ \\
\hline Facility location & $\begin{array}{l}\text { Customer aggregation (22\% of total) for real-world capacitated facility } \\
\text { location problem: Sankaran [91]. Francis, et al. [37]: on error bounds for } \\
\text { location models. }\end{array}$ \\
\hline Distribution system & $\begin{array}{l}\text { See Gavriliouk [41] for hub location (six models) via aggregation of } \\
\text { networks of 300 to 1000 nodes }\end{array}$ \\
\hline Lot size & $\begin{array}{l}\text { Very interesting work on real-world replenishment/ shortfalls of usual } \\
\text { models, introducing 'family' clusters for lot sizing: Lenard and Roy [69] }\end{array}$ \\
\hline
\end{tabular}

Selection designates the focused viewing of detailed data involving a reduction in complexity. The aim is to disregard or remove data which is less interesting or redundant for the overall objective. The result is a selected input size $n_{s}<n_{o}$, the original size. This can be performed iteratively. Three methods have been identified: Prioritization signifies a (temporarily) narrowed consideration of the problem, i.e. the selection of subsets of data in order to enhance the solution efficiency. Domination identifies data or data sets that are superior to other data or data sets as it seeks to "eliminate uninteresting assignments or select interesting ones", reducing search space through the addition of new constraints, keeping at least one optimum ([59]). Reduction considers input on the basis of specified properties (e.g., correlations) that are usual to optimums ([98], p. 158).

Example: Church [13] simplifies a planar maximal-covering location problem in two steps (before applying a linear programming solver): At first, all $n$ demand points are encircled by disks of radius $S$, the maximum service distance. The result is a circle intersect point set (CIPS) containing all demand points as well as all circle intersections, i.e., at most $n^{2}$ members. Due to a possibly large CIPS size resulting in a rather high computing effort, a reduced CIPS is then created by dropping dominated points, i.e. those whose coverage is less than or equal to the coverage of other members. The results of Church on the basis of the 55node problem show that the RCIPS is "usually quite small" - this second step reduces the set by up to $99 \%$.

Table 3. Continuative Sources on Selection

\begin{tabular}{|l|l|}
\hline Type & Sources \\
\hline General & $\begin{array}{l}\text { Work on dominance rules in combinatory optimization (definitions, types, } \\
\text { a.o.), by Jouglet and Calier [59] }\end{array}$ \\
\hline Bin packing & $\begin{array}{l}\text { Martello and Toth [74] use a dominance criterion to reduce the size of a } \\
\text { bin packing problem. Pisinger [89] gives priority rules for item selection } \\
\text { optimizing packing density. }\end{array}$ \\
\hline Vehicle routing & $\begin{array}{l}\text { Erera [34] routes vehicles in their pick-up dynamically, based on } \\
\text { prioritized zones. Golden [43] reduces a traveling salesman problem by } \\
\text { considering only 'neighbors' in a grid. }\end{array}$ \\
\hline
\end{tabular}

Derivation, used in the case of uncertainty (see, for example, [101] (p. 538) for a definition), builds on data which is incompletely known but complemented by experience and estimates. Its description using probability distributions, adapted to the given environment, allows an optimization on the basis of involved characteristics (expected value, variance, quantile, etc.,). The use of point/ interval estimation of the optimum (based on sampling) is closely related to this. In case of no prior probabilistic information, specifications need to be 
made: scenario approaches, in which decision makers define possible future states in order to generate solutions that work well in all cases ([84], p. 441).

Example: Gudehus and Kotzab [47] (p. 296f.) give an easily comprehensible formula for securing stock availability during replenishment time $t$ based on a given service requirement $\alpha$. The stochastics of demand are depicted in it via normal distribution $N(\mu, \sigma)$, giving a good approximation "due to the law of large numbers [...] within a longer replenishment time". The safety stock level $s$, ensuring the ability to deliver with the required probability, is then determined by $p(\alpha) \cdot(t \mu+\sqrt{t} \sigma)$, with the safety factor $p$ given by the inverse standard normal distribution (e.g. $p(0.98) \approx 2.05$ ), multiplied by the expected order size plus demand variability during $t$.

Table 4. Continuative Sources on Derivation

\begin{tabular}{|l|l|}
\hline Type & Sources \\
\hline Facility location & $\begin{array}{l}\text { Snyder [101] gives approaches / applications of stochastic and robust } \\
\text { facility location models. Overview on facility location research considering } \\
\text { time and uncertainty by Owen and Daskin [84]. }\end{array}$ \\
\hline Lot size & $\begin{array}{l}\text { Naddor [85] analyses inventory systems based only on key figures instead } \\
\text { of distributions. }\end{array}$ \\
\hline Bin packing & $\begin{array}{l}\text { Description of bin packing process via Markov chain properties, authored } \\
\text { by Coffman, et al. [16] }\end{array}$ \\
\hline Vehicle routing & $\begin{array}{l}\text { Kocacs and Goodin [65] select the most probable minimum path based on } \\
\text { statistical characteristics. Confidence interval procedures for intractable } \\
\text { optimization problems (traveling salesman example) are given by Golden } \\
\text { and Alt [44]. Bertsimas and van Ryzin [8] propose policies for the dynamic } \\
\text { traveling repairman problem (on-site time!) using queuing theory. }\end{array}$ \\
\hline
\end{tabular}

Opportunism describes an action taken without foresight under the demand of immediate utility maximization without regard to the overall utility, i.e., a "locally optimal choice in the hope that this will lead to a globally optimal solution" ([108]). The overall solution is composed of the in every step best partial solution of the solution procedure. This 'greedy' approach is often easily applicable due to its simplicity, and can therefore serve as a compromise between effort and benefit. This principle is based on a sorting of the input set and the selection of the best element from an objective's perspective. As a result, the combinatory complexity of the problem is avoided. A sorting is usually described by super linear growth, i.e., $\mathcal{O}(n \log n)$ - there are about $n$ possibilities. By comparison, a combinatory solution has exponential growth, i.e., $\Omega\left(c^{n}\right)$ with $c>1-$ there are approximately $n$ ! possibilities. However, opportunism is not an 'all-purpose tool' as its application requires consideration: depending on the optimization problem, it finds optimal solutions ([108]) as well as "unique worst possible solutions", "impractical even for generating a starting solution" ([6]).

Example: Kruskal [66] describes a greedy algorithm used to determine minimal span trees, i.e. a special shortest-path problem (including all nodes). The procedure is quite simple: 1) sort all edges by weights, lowest first, then 2) start with the first edge, 3) add the next edge, regardless of its connection to the previous edge, and 4) repeat the third step for all other edges, skipping those that lead to cycles within a subgraph. 
Table 5. Continuative Sources on Opportunism

\begin{tabular}{|l|l|}
\hline Type & Sources \\
\hline General & Curtis [20]: the theory of greedy algorithms for modelers. \\
\hline Facility location & $\begin{array}{l}\text { Greedy approach to the capacitated problem adding/ dropping locations } \\
\text { with highest savings/ costs, found in Sridharan [102] }\end{array}$ \\
\hline Distribution system & $\begin{array}{l}\text { Interesting approach on inventory routing, connecting the most urgent } \\
\text { customer with the most appropriate vehicle: Savelsberg and Song [92] }\end{array}$ \\
\hline Bin packing & $\begin{array}{l}\text { Johnson, et al. [57] and their well-known First-fit (decreasing) and Best-Fit } \\
\text { (decreasing) algorithms. }\end{array}$ \\
\hline Vehicle routing & $\begin{array}{l}\text { Clarke and Wrights's [14] algorithm creates tours on the basis of highest } \\
\text { savings. }\end{array}$ \\
\hline
\end{tabular}

Division is characterized by principles of analysis and segmentation, transforming the overall problem into subproblems which are easier to handle and subsequently solved and recombined - the 'divide and conquer' approach: a large input set of size $n_{o}$ is partitioned into subsets of sizes $n_{p}<n_{o}$, a multi-dimensional problem is 'reduced', and so on. Depth of detail and the entirety of the information are preserved, yet not necessarily considered. The final result is often based on iterative development, choice, dimensioning and the combination of partial solutions ([48], p. 123). Decomposition is used when the subproblems are not independent of each other, i.e. the output of one is input to the next ([113], p. 90).

Example: Lodi, et al. [72] introduce the very effective Height first-Area second method for three-dimensional bin-packing, consisting of two phases which seek to balance vertical and horizontal filling. Phase 1 clusters the items by height, then sorts them by area within each cluster, and numbers them. Then, procedure PACK is run: Beginning with the first item, counting up, layers are filled in the following order, based on a packing pattern (the leftmost or hindmost, with the positions being evaluated according to contact surface, filling level and relative height): if available, choose a layer of a height no less than that of the item in focus, otherwise and if available, choose a layer of lesser height, increasing its height to the item's; otherwise open up a new layer. The layers are finally sorted by a one-dimensional binpacking algorithm. Phase 2 clusters and numbers the items directly by area. The layers of Phase 1 (now empty, but the same height) are now filled by PACK again. The better solution using fewer bins is chosen.

Functionalization is based on the linking of data within a set relation, i.e. function argument and function value are assigned to each other, which is more simplified solvable mathematically due to its function attributes (especially differentiability). The procedure is based on continuous variables embedded within the function, allowing an optimal specification of their value in regard to the overall function value. Due to the continuous, i.e. stepless basis and its attendant robustness, functionalization results in rather stable solutions in the face of uncertainty. The approach's difficulty lies mostly in the determination of the functional correlation, yet it then provides a better understanding of the matter, e.g., of tradeoffs ([68], p. 183). 
Table 6. Continuative Sources on Division

\begin{tabular}{|l|l|}
\hline Type & Sources \\
\hline Facility location & $\begin{array}{l}\text { Vahrenkamp and Mattfeld's [109] Grid heuristic 'stamps' locations on a } \\
\text { plane (p. 147f.). Church [13] simplifies a covering location problem } \\
\text { 'graphically'. }\end{array}$ \\
\hline Distribution system & $\begin{array}{l}\text { The Hierarchical routing of Daganzo [21] (p. 233ff.) assigns hubs according } \\
\text { to a certain grid logic. Campbell and Savelsbergh [11] decompose an } \\
\text { inventory routing problem located in the gas industry, first creating the } \\
\text { schedules, then the routes. }\end{array}$ \\
\hline $\begin{array}{l}\text { Gillet and Miller's [42] well-known Sweep algorithm partitions customers } \\
\text { by polar coordinates. Interesting strip method by Daganzo [23], simplifying } \\
\text { the tour building by fragmenting the plane. Boa and Liu [7] solve a } \\
\text { clustered traveling salesman problem by first determining the order of the } \\
\text { clusters, then the order of the vertices within. }\end{array}$ \\
\hline
\end{tabular}

Example: Hall [52] compares one- and two-terminal routing on the basis of expected distances in a grid-covered region, with each terminal being the center of its square zone. He sets up the following functional connections: The average transport distance $L_{1}+L_{2}$ for one terminal (respectively $2 L_{1}+L_{3}$ for two terminals) consists of the average distance between the origin and its terminal plus the average distance between the same terminal and the destination (or the average distance between any source/ sink and the terminal next to it plus the average distance between two terminals). The total network length, i.e. all combinations of average lengths, then amounts to $M L_{1}+(I J) N L_{2}$ for one terminal (or $(M+N) L_{1}+$ $(I J)^{2} L_{3}$ for two terminals), covering $M$ sources and $N$ sinks in $I J$ grid zones. He concludes that the average distance of the one-terminal routing is never higher than that of two-terminal routing, and yet, in dependence of $M, N, I, J$, total network length can be more advantageous if two terminals are used. (For this derivation please consult the work.) Hall illustrates his approach using commerce flows between the 37 largest U.S. cities.

Table 7. Continuative Sources on Functionalization

\begin{tabular}{|l|l|}
\hline Type & Sources \\
\hline General & $\begin{array}{l}\text { Daganzo [21], the 'Hector' of continuous approximation and its work on } \\
\text { logistics systems. Differences between discrete and continuous modeling } \\
\text { are pointed out by Hall [51] }\end{array}$ \\
\hline Distribution system & $\begin{array}{l}\text { Janáček and Buzna [56] contrast cont. approx. with math. program. in a } \\
\text { hub location problem. Nice work of Mangotra, et al. [74] on facility } \\
\text { location/ inventory allocation in two echelons and a (s,Q) policy. On ideal } \\
\text { network shapes: Daganzo and Newell [24]. }\end{array}$ \\
\hline Lot size & $\begin{array}{l}\text { Introductory example by Daganzo [21] (Ch. 3.3.4). Note Muckstadt and } \\
\text { Sapras [80] book on inventory management for several examples. }\end{array}$ \\
\hline Vehicle routing & $\begin{array}{l}\text { Del Castillo [25] and his extensive work solving the traveling salesman by } \\
\text { cont. approx. partitions, similar to Daganzo's strip method. Hall, et al. [50] } \\
\text { applies findings of cont. approx.. within discrete vehicle routing. }\end{array}$ \\
\hline
\end{tabular}

Randomization refers to the use of stochastic components in the context of solution procedures. Used in regard to the method itself, a randomized algorithm "can be viewed as a probability distribution on a set of deterministic algorithms" ([45], p. 572) that complement each other in their performance and therefore are most likely to yield a suitable working procedure for every input, "foiling the adversary" ([62], p. 197). Used in regard to the input set, a randomized algorithm examines a problem through "random sampling, ordering and 
partitioning" ([62], p. 197), resulting in a reduction in complexity. Furthermore, systematic errors such as getting stuck in local optima can be avoided. (A frequent benefit of meta heuristics.)

Example: Schrimpf, et al., [95] introduce a promising approach ("record-breaking optimization results") based on "ruin and recreate": parts of an existing solution are destroyed in order to be reestablished optimally. For example, a traveling salesman's route is partially erased, i.e. customers are removed from the trip, only to locally create a new and improved solution that is finally reconnected to the 'loose ends'. There are different methods of ruin radial, random, and sequential are used - yet all include random components; the recreation can apply randomness as well, depending on the chosen algorithm, e.g., simulated annealing. Overall, Schrimpf, et al., specify the following process: 1) create an initial solution; 2) ruin it (choose a method); 3) recreate (choose an algorithm); 4) if you accept the result (depending on a decision rule, e.g., simulated annealing), go to 2 ) using the new solution, otherwise go to 2) using the old solution.

Table 8. Continuative Sources on Randomization

\begin{tabular}{|l|l|}
\hline Type & Sources \\
\hline General & $\begin{array}{l}\text { Great overview on meta heuristics (pseudo code description - note usage } \\
\text { of 'random'), provided by Boussaid, et al. [9]. On randomization in online } \\
\text { algorithms see Albers [1] (p. 5f.). }\end{array}$ \\
\hline Facility location & Meyerson's [78] randomized algorithms for online facility location. \\
\hline Distribution system & $\begin{array}{l}\text { Jayaraman and Ross [57]: interesting work on a retailer's distribution } \\
\text { network using simulated annealing. }\end{array}$ \\
\hline Bin packing & $\begin{array}{l}\text { Corcoran and Wainwright [15] introduce a genetic algorithm for 3D bin } \\
\text { packing. }\end{array}$ \\
\hline
\end{tabular}

Mechanization stands for the transformation and solution of a mathematical problem in a mechanical model, enabling a direct interaction with the modeler within its higher degrees of freedom. In this, it constitutes an alternative draft or addition to a mathematical-conceptual approach that overcomes its structural restrictions through manual liberties. The probably best-known example of mechanization is the Varignon apparatus (see e.g., [32] (Ch. 1.3.4)), which solves a planar warehouse location problem. Although there are newer examples - see e.g., [28] (p. 47ff.) - complete mechanical solutions seem to be of more creative interest.

Example: Newell [87] handles a warehouse location problem using "continuum mechanics", i.e., a manual solution based on insights in continuous approximation. The following is given: a plane of uniformly distributed demand is optimally served by circular (or packing hexagonal) regions, sizes all alike due to the dependence on demand level. But what happens in the case of demand variations? The minimum cost then requires locating the minimal costs per unit demand all over the plane, and distributing centers whose region sizes match the local demand level. How to do this? Cut circular disks of locally optimal radii from soft material, lay them on their regions on the plane, packing them to nearly cover it. Then choose the centers, and assign uncovered points to the nearest centers by "forcing" the material "to fill any large holes" through the use of pressure. 
Table 9. Continuative Sources on Mechanization

\begin{tabular}{|l|l|}
\hline Type & Sources \\
\hline Facility location & $\begin{array}{l}\text { Hitchings [54] presents an electric solution for the Weber problem, a } \\
\text { modern Varginon apparatus so to speak. }\end{array}$ \\
\hline $\begin{array}{l}\text { Distribution } \\
\text { system }\end{array}$ & $\begin{array}{l}\text { Miehle [79] solves a network problem, moving hubs via strings in a } \\
\text { complex installation. }\end{array}$ \\
\hline Vehicle routing & $\begin{array}{l}\text { A shortest path solution realized through bricks and distance proportional } \\
\text { strings (Domschke and Drexl [29], p. 47 f.) }\end{array}$ \\
\hline
\end{tabular}

Termination ends a solution procedure (in part or entirely) based on previously defined criteria such as a limitation of run time or a satisfying solution quality. The reasons for this are the increase of computational efficiency through the partial exclusion of the input set (complexity reduction), or a balancing of the cost and utility of an entire computation. A partial termination is especially common in the context of branch and bound approaches (and related forms) that use boundary procedures to focus their efforts on promising branches alone - all others are bound.

Example: Hart, et al., [53], with their $\mathrm{A}^{*}$ algorithm, show a shortest-path method that dynamically evaluates which cost-optimal (sub)branch to take within a (sub)graph. From the perspective of node $s$, an evaluation function $f(n)=g(n)+h(n)$ determines a look-ahead value for every successive node $n$ consisting of the known cost $g(n)$ to get from $s$ to $n$ and the estimated cost $h(n)$ to get from $n$ to a target node $t \in T$. The $n$ with the smallest $f(n)$ is chosen, and marked 'closed', after which all its successors are 'opened' (unless they are marked closed or better evaluated than at their time of closure) and considered. The set of open nodes allows a permanent comparison of the current costs with prior levels and the correction of 'wrong' decisions as more information becomes known (requiring a return to previous nodes). The estimator $h(n)$ is not set, yet needs to be an infimum, the lower bound, of the subproblem, e.g., the Euclidian distance; its individual selection allows a "compromise between admissibility, heuristic effectiveness, and computational efficiency" ([53], p 107).

Table 10. Continuative Sources on Termination

\begin{tabular}{|l|l|}
\hline Type & Sources \\
\hline General & On branch and bound, see e.g. Wagenknecht [110] (Ch. 6). \\
\hline Facility location & $\begin{array}{l}\text { Suzuki and Drezner [105] terminate the improvement of a Voronoi diagram } \\
\text { in case of too small changes. }\end{array}$ \\
\hline Vehicle routing & $\begin{array}{l}\text { Good introduction to the branch and bound approach, using the traveling } \\
\text { salesman problem: Balas and Toth [4] }\end{array}$ \\
\hline
\end{tabular}

Threshold values simplify problems by being embedded in tasks of larger solution space which are easier to solve, in part due to different solution procedures. The coarsening allows a first estimation or containment of the result. A well-known application of this principle is the technique of relaxation that dissolves restrictions: e.g., the Lagrange relaxation, transferring "difficult" restrictions to the objective function using penalty costs, thus converting so a mixed-integer problem to a non-linear optimization - see [46]. Lower bound procedures, which assign superior characteristics to (parts of) elements/ sets by ignoring restrictions (e.g., indivisibility) or generalizing individual properties (e.g., gain), are closely related. The outcome may serve as a benchmark for "quality of solution [...] through comparison", or to "obtain an enumerative algorithm for exact solution", according to [75] (p. 60). Approximation schemes (requiring the input of an additional parameter $\varepsilon>0$, the desired approximation ratio) yield solutions of a quality which improves with run time. However, 
depending on its type, run time may rise disproportionately with sinking $\varepsilon$; thus one distinguishes between quasi-polynomial and fully polynomial schemes - see, for example, [96]. Often, the problem which is to be solved is embedded in a larger problem, e.g., via relaxations ([110], p. 169).

Example: Martello and Toth [75] exemplify that the application of threshold values can be a great compromise between quality (their solution is often optimal) and speed (very high). Their lower bound approach for bin packing uses 'interval sorting': $i$ items of weight $w_{i}$ need to be placed into a minimum number of bins of capacity $C$. Given there is any integer $K$ with $0 \leq K \leq C / 2$, then items are assigned according to the following key: large and mediumsized items $w_{i}>C-K$ and $C-K \geq w_{i}>C / 2$ each get their own bins, small items $C / 2 \geq w_{i} \geq K$, assumed to be splittable, are finally used to fill empty space within the second category; and if that is not completely possible, a new bin is opened. The choice of $K$ depends on the weight distribution - if there is an emphasis on high (low) weights, $K$ will be closer to $C / 2$ (to 0 ), opening up more bins of the first (second) category which are not (are) used for later filling.

Table 11. Continuative Sources on Threshold Values

\begin{tabular}{|l|l|}
\hline Type & Sources \\
\hline General & $\begin{array}{l}\text { Exemplifying different approaches: LP relaxation (Neumann and Morlock } \\
\text { [83], Ch. 1), Surrogate relaxation (Domschke, Scholl [30]), Variable } \\
\text { splitting relaxation (Cornuejols, et al. [17]) }\end{array}$ \\
\hline Facility location & $\begin{array}{l}\text { Cornuejols, et al. [17] discuss several relaxations for the capacitated plant } \\
\text { location problem. Approximation scheme for the Euclidean p-median } \\
\text { problem: Kolliopoulos and Rao [65] }\end{array}$ \\
\hline Distribution system & $\begin{array}{l}\text { Skorin-Kapov, Skorin-Kapov and O'Kelly: lower bounds of a hub location } \\
\text { problem [89], LP relaxed p-hub median problems [101] }\end{array}$ \\
\hline Lot size & Approximation scheme (single-item, discrete demand), by Orlin, et al. [84] \\
\hline Bin packing & $\begin{array}{l}\text { Crainic, et al. [19] deal with fast lower bounds (tight, limited computational } \\
\text { effort) on bin packing. }\end{array}$ \\
\hline Vehicle routing & $\begin{array}{l}\text { An approximation scheme for the shortest path problem - Lorenz and Raz } \\
\text { [73] - and for the Euclidean traveling salesman problem - Arora [3]. }\end{array}$ \\
\hline
\end{tabular}

Solution space describes a set of solutions instead of one final result - a unique value is not given. It constitutes thus a preprocessing of a model. The final 'localization' of the solution is either left to the decision-maker or further algorithmic development, possessing information not contained within the model. The reason for this can be a generalization of a problem through the suppression of restrictions and a resulting enhanced flexibility.

Example: Melachrinoudis and Xanthopulos [76] describe the solution of a semi-obnoxious facility - like a waste dump -, i.e., maximizing the minimal distance between facility and locations (maximin objective) while minimizing the distance to all locations (minisum objective). The former usually seeks places that are at the edge of a region, the latter often places facilities between locations - two very different, contrary tasks; both are to be looked at simultaneously in order to yield compromises for the modeler to decide on. They therefore introduce a tradeoff rate representing "the amount of improvement gained in the maximin objective by selecting another [...] solution [...] in which the transportation cost, represented by the minisum objective, increases by a unit". The final result is a set of segments that display all possible solutions, according to the weighting of the problems. 
Table 12. Continuative Sources on Solution Space

\begin{tabular}{|l|l|}
\hline Type & Sources \\
\hline Facility location & Farahani, et al. [35] give a survey on multi-criteria facility location models. \\
\hline Distribution system & $\begin{array}{l}\text { Daganzo [21] outlines liberties in implementing cont. approx. solutions (p. } \\
\text { 177). }\end{array}$ \\
\hline Vehicle routing & $\begin{array}{l}\text { Overview on vehicle routing with multiple objectives: Jozefowiez, et al. [59] } \\
\text { (Ch. 4.2). Interesting work on multigraphs for on-demand transportation } \\
\text { from Garaix, et al. [40]. }\end{array}$ \\
\hline
\end{tabular}

For further explanation regarding the classification (e.g., the reasoning behind the alignment of principles and mechanisms) as well as an elaborate description of examples, see Gumpp [49].

\section{Synthesis}

Many logistics problems are of a very complex nature that stands in contrast to the requirements of practice (e.g., in the case of multi-agent systems): simplicity and speed. Due to this gap, methods that align theory and application are necessary. However, the wide variety of solution and simplification procedures (that are often quite specific in terms of their applicability) impedes their usage. The review of comparable settings is starting point for practitioners in their need for orientation, as they lack overview.

This work seeks to support them through a classification of simplification principles that gives a choice of alternatives as to how a problem can be approached. It classifies them according to their starting point:

* Model input: aggregation, selection and derivation.

* Solution procedure: opportunism, division, functionalization, randomization and mechanization.

* Model output: termination, threshold value and solution space.

Each principle is specified using one or more examples that aim to increase its understanding as well as of its possible different occurrences. With this, the paper smoothes the way for a general reflection on transformation approaches in optimization. In literature a variety of ideas exist that have been developed in order to conquer the complexity of logistics optimization. The authors seek to contribute to a structure which makes the existing knowledge available to practitioners - otherwise it will remain mostly unused. A possible next step in a future work is the evaluation and collocation of principles and problems regarding their effectiveness and efficiency.

\section{References}

[1] S. Albers, "Online Algorithms: a Survey", Mathematical Programming, Ser. B, vol. 97, no. 3, (2003).

[2] G. Andersson, R. L. Francis, T. Normark and M. B. Rayco, "Aggregation Method Experimentation for Large-Scale Network Location Problems”, Location Science, vol. 6, no. 25, (1998).

[3] S. Arora, "Polynomial Time Approximation Schemes for Euclidean Traveling Salesman and Other Geometric Problems", Journal of the ACM, vol. 45, no. 5, (1998), pp. 753.

[4] E. Balas and P. Toth, "Branch and Bound Methods for the Traveling Salesman Problem", Management Science Research Report No. MSRR, (1983), pp. 488.

[5] M. Ball and M. Magazine, "The Design and Analysis of Heuristics”, Networks, vol. 11, no. 215, (1981). 
[6] J. Bang-Jensen, G. Gutin and A. Yeo, "When the Greedy Algorithm Fails", Discrete Optimization, vol. 1, no. 121, (2004).

[7] X. Bao and Z. Liu, "An Improved Approximation Algorithm for the Clustered Traveling Salesman Problem”, Information Processing Letters, vol. 112, no. 908, (2012).

[8] D. J. Bertsimas and G. van Ryzin, "A Stochastic and Dynamic Vehicle Routing Problem in the Euclidean Plane”, Operations Research, vol. 39, no. 4, (1991), pp. 601.

[9] I. Boussaïda, J. Lepagnot and P. Siarry, "A Survey on Optimization Metaheuristics", Information Sciences, vol. 237, no. 82, (2013).

[10] K. H. Borgwardt, "Operations Research - Spieltheorie: Mathematische Grundlagen”, Birkhäuser, Ed. 1, (2001).

[11] A. M. Campbell and M. W. P. Savelsbergh, "A Decomposition Approach for the Inventory-Routing Problem", Transportation Science, vol. 38, no. 4, (2004), pp. 488.

[12] J. Y. J. Chow, C. H. Y. Yang and A. C. Regan, "State-of-the-Art of Freight Forecast Modeling: Lessons Learned and the Road Ahead, Transportation, vol. 37, no. 6, (2010), pp. 1011.

[13] R. Church, "The Planar Maximal Covering Location Problem”, Journal of Regional Science, vol. 24, no. 2, (1984), pp. 185.

[14] G. Clarke and J. W. Wright, "Scheduling of Vehicles from a Central Depot to a Number of Delivery Points", Operations Research, vol. 12, no. 4, (1964), pp. 568.

[15] A. L. Corcoran, III and R. L. Wainwright, "A Genetic Algorithm for Packing in Three Dimensions", Proceedings of the 1992 ACM/SIGAPP Symposium on Applied Computing, 1021, Kansas City, USA, (1992) March 01-March 03

[16] E. G. Coffman, Jr., K. So, M. Hofri and A. C. Yao, "A Stochastic Model of Bin-Packing, Information and Control, vol. 44, no. 2, (1980), pp. 105.

[17] G. Cornuejols, R. Sridharan and J. M. Thizy, "A Comparison of Heuristics and Relaxations for the Capacitated Plant Location Problem”, European Journal of Operational Research, vol. 50, (1991), pp. 280.

[18] T. H. Cormen, C. E. Leiserson, R. L. Rivest and C. Stein, "Clifford, Introduction to Algorithms", MIT Press, Ed. 9, (2009).

[19] T. G. Crainic, G. Perboli, M. Pezzuto and R. Tadei, "New Bin Packing Fast Lower Bounds", Computers \& Operations Research, vol. 34, (2007), pp. 3439.

[20] S. A. Curtis, "The Classification of Greedy Algorithms", Science of Computer Programming, vol. 49, no. 13, (2003), pp. 125.

[21] C. F. Daganzo, "Logistics Systems Analysis", Springer, (2005).

[22] C. F. Daganzo, "Increasing Model Precision Can Reduce Accuracy", Transportation Science, vol. 21, no. 2, (1987), pp. 100.

[23] C. F. Daganzo, "The Length of Tours in Zones of Different Shapes", Transportation Research Part B: Methodological, vol. 18, no. 2, (1984), pp. 135.

[24] C. F. Daganzo and G. F. Newell, "Configuration of Physical Distribution Networks", Networks, vol. 16, no. 2, (1986), pp. 113.

[25] J. M. Del Castillo, "A Heuristic for the Traveling Salesman Problem Based on a Continuous Approximation”, Transportation Research Part B, vol. 33, (1999), pp. 123.

[26] G. De Jong, H. Gunn and W. Walker, "National and International Freight Transport Models: An Overview and Ideas for Future Developments", Transport Reviews, vol. 24, no. 1, (2004), pp. 103.

[27] K. A. Downsland and W. B. Downsland, "Packing Problems", European Journal of Operational Research, vol. 56, no. 1, (1992), pp. 2.

[28] W. Domschke, "Logistik: Transport”, Oldenbourg, Ed., vol. 5, (2007).

[29] W. Domschke and A. Drexl, "Logistik: Standorte", Oldenbourg, Ed., vol. 4, (1996).

[30] W. Domschke and A. Scholl, "Logistik: Rundreisen und Touren", Oldenbourg, Ed., vol. 5, (2010).

[31] A. Drexl and A. Kimms, "Lot sizing and Scheduling-Survey and Extensions", European Journal of Operational Research, vol. 99, no. 2, (1997), pp. 221.

[32] Z. Drezner, K. Klamroth, A. Schöbel and G. O. Wesolowsky, "Facility Location: Applications and Theory", Edited Z. Drezner, H. W. Hamacher, Springer, Ch. 1 "The Weber Problem", Ed., vol. 1, (2004).

[33] B. Eksioglu, A. V. Vural and A. Reisman, "The Vehicle Routing Problem: a Taxonomic Review", Computers \& Industrial Engineering, vol. 57, (2009), pp. 1472.

[34] A. L. Erera, "Design of Large-Scale Logistics Systems for Uncertain Environments", University of California, Berkeley, Institute of Transportation Studies, Dissertation, (2000).

[35] R. Z. Farahani, M. SteadieSeifi and N. Asgari, "Multiple Criteria Facility Location Problems: a Survey", Applied Mathematical Modelling, vol. 34, no. 7, (2010), pp. 1689.

[36] R. Z. Farahani and M. Hekmatfar, "Facility Location: Concepts", Models, Algorithms and Case Studies, Edited R. Z. Farahani, M. Hekmatfar, Physika, Ed., Ch. Introduction, vol. 1, (2009). 
[37] R. L. Francis, T. J. Lowe and A. Tamir, "Aggregation Error Bounds for a Class of Location Models", Operations Research, vol. 48, no. 2, (2000), pp. 294.

[38] H. Friedrich, "Simulation of Logistics in Food Retailing for Freight Transportation Analysis", Karlsruher Institut für Technologie, Institut für Wirtschaftspolitik und Wirtschaftsforschung, Dissertation, (2010).

[39] M. Fuchsenberger, "Bestellmengenmodelle im Lebensmittelhandel - Gegenüberstellung von Theorie und Praxis", Universität Karlsruhe (TH), Institut für Wirtschaftspolitik und Wirtschaftsforschung, Diploma Thesis, (2009).

[40] T. Garaix, C. Artigues, D. Feillet and D. Josselin, "Vehicle Routing Problems with Alternative Paths: an Application to On-Demand Transportation", European Journal of Operational Research, vol. 204, no. 62, (2010).

[41] E. O. Gavriliouk, "Aggregation in Hub Location Problems", Computers \& Operations Research, vol. 36, no. 12, (2009), pp. 3136.

[42] B. E. Gillett, L. R. Miller and A Heuristic, "Algorithm for the Vehicle-Dispatch Problem", Operations Research, vol. 22, no. 2, (1974), pp. 340.

[43] B. L. Golden, “A Statistical Approach to the TSP”, Networks, vol. 7, no. 209, (1977).

[44] B. L. Golden and F. B. Alt, "Interval Estimation of a Global Optimum for Large Combinatorial Problems", Naval Research Logistics Quarterly, vol. 26, no. 1, (1979), pp. 69.

[45] C. P. Gomes and R. Williams, "Search Methodologies: Introductory Tutorials in Optimization and Decision Support Techniques”, Edited K. E. Burke, G. Kendall, Springer, Ch. Approximation Algorithms, (2005).

[46] T. Grünert and S. Irnich, “Optimierung im Transport”, Band 1: Grundlagen, Shaker, Ed., vol. 1, (2005).

[47] T. Gudehus and H. Kotzab, "Comprehensive Logistics", Springer, (2009).

[48] T. Gudehus, "Logistik: Grundlagen - Strategien - Anwendungen”, Springer, Ed., vol. 4, (2010).

[49] J. Gumpp, "Vereinfachte Modellierung und Lösung logistischer Optimierungsprobleme", Karlsruher Institut für Technologie, Institut für Wirtschaftspolitik und Wirtschaftsforschung, Diploma Thesis, (2011).

[50] R. W. Hall, Y. Du and J. Lin, "Use of Continuous Approximations within Discrete Algorithms for Routing Vehicles: Experimental Results and Interpretation”, Networks, vol. 24, no. 43, (1994).

[51] R. W. Hall, "Discrete Models/ Continuous Models", International Journal of Management Science, vol. 14, no. $213,(\mathbf{1 9 8 6})$.

[52] R. W. Hall, "Travel Distance Through Transportation Terminals on a Rectangular Grid", The Journal of the Operational Research Society, vol. 12, no. 35, (1984).

[53] P. E. Hart, N. J. Nilsson and B. Raphael, "A Formal Basis for the Heuristic Determination of Minimum Cost Paths", IEEE Transaction of System Science and Cybernetics, vol. 4, no. 2, (1968), pp. 100.

[54] G. G. Hitchings, "Analogue Techniques for the Optimal Location of a Main Facility in Relation to Ancillary Facilities”, International Journal of Production Research, vol. 7, no. 3, (1968), pp. 189.

[55] J. Hromkovič, "Randomisierte Algorithmen: Methoden zum Entwurf von Zufallsgesteuerten Systemen für Einsteiger", Teubner, Ed., vol. 1, (2004).

[56] J. Janáček and L. Buzna, "A Comparison Continuous Approximation with Mathematical Programming Approach to Location Problems", Central European Journal of Operations Research, vol. 12, (2004), pp. 295.

[57] V. Jayaraman and A. Ross, "A Simulated Annealing Methodology to distribution network design and management”, European Journal of Operational Research, vol. 144, (2003), pp. 629.

[58] D. S. Johnson, A. Demers, J. D. Ullman, M. R. Garey and R. L. Graham, "Worst-Case Performance Bounds for Simple One-Dimensional Packing Algorithms", SIAM Journal on Computing, vol. 3, no. 4, (1974), pp. 299.

[59] N. Jozefowiez, F. Semet and E. Talbi, "Multi-Objective Vehicle Routing Problems", European Journal of Operational Research, vol. 189, no. 293, (2008).

[60] A. Jouglet and J. Carlier, "Dominance Rules in Combinatorial Optimization Problems", European Journal of Operational Research, vol. 212, no. 433, (2011).

[61] B. Karimi, S. M. T. F. Ghomi and J. M. Wilson, "The Capacitated Lot Sizing Problem: a Review of Models and Algorithms", Omega, vol. 31, no. 5, (2003), pp. 365.

[62] R. M. Karp, "An Introduction to Randomized Algorithms", Discrete Applied Mathematics, vol. 34, no. 165, (1991).

[63] L. Kaufman and P. J. Rousseeuw, "Finding Groups in Data: An Introduction to Cluster Analysis", Wiley, (2005).

[64] A. Klose and A. Drexl, "Facility Location Models for Distribution System Design", European Journal of Operational Research, vol. 162, no. 1, (2005), pp. 4.

[65] S. G. Kolliopoulos and S. Rao, "A Nearly Linear-Time Approximation Scheme for the Euclidean k-Median Problem”, SIAM Journal on Computing, vol. 37, no. 3, (2007), pp. 757.

[66] W. J. Kocacs and D. T. Goodin, "A Statistical Approach to the Traveling Salesman Problem”, Transportation Research: B, vol. 199, no. 3, (1985), pp. 239. 
[67] J. B. Kruskal, Jr., "On the Shortest Spanning Subtree of a Graph and the Traveling Salesman Problem”, Proceedings of the American Mathematical Society, vol. 7, no. 1, (1956), pp. 48.

[68] A. Langevin, P. Mbaraga and J. F. Campell, "Continuous Approximation Models of Freight Distribution: an Overview", Transportation Research: Part B, vol. 30, no. 3, (1996), pp. 163.

[69] G. Laporte, "Fifty Years of Vehicle Routing", Transportation Science, vol. 43, no. 4, (2009), pp. 408.

[70] J. D. Lenard and B. Roy, "Multi-Item Inventory Control: a Multicriteria View", European Journal of Operational Research, vol. 87, (1995), pp. 685.

[71] I. Litvinchev and V. Tsurkov, "Aggregation in Large-Scale Optimization", Kluwer Academic Publisher, (2003).

[72] A. Lodi, S. Martello and D. Vigo, "Heuristic Algorithms for the Three-Dimensional Bin Packing Problem", European Journal of Operational Research, vol. 141, no. 410, (2002).

[73] D. H. Lorenz and D. Raz, "A Simple Efficient Approximation Scheme for the Restricted Shortest Path Problem", Operations Research Letters, vol. 28, no. 5, (2001), pp. 213.

[74] D. Mangotra, J. Lu and Y. Tsao, "A Continuous Approximation Approach for the Integrated Facility Location-Inventory Allocation Problem”, ISyE Technical Report J-09-01, (2001).

[75] S. Martello and P. Toth, "Lower Bounds and Reduction Procedures for the Bin Packing Problem", Discrete Applied Mathematics, vol. 28, no. 59, (1990).

[76] E. Melachrinoudis and Z. Xanthopulos, "Semi-Obnoxious Single Facility Location in Euclidean Space", Computers \& Operations Research, vol. 30, (2003), pp. 2191.

[77] M. T. Melo, S. Nickel and F. Saldanha-da-Gama, "Facility Location and Supply Chain Management - a Review”, European Journal of Operational Research, vol. 196, no. 2, (2009), pp. 401.

[78] A. Meyerson, "Online Facility Location", Proceedings of the 42nd IEEE Symposium on Foundations of Computer Science, Las Vegas, USA, (2001) October 14-October 17, pp. 426.

[79] W. Miehle, "Link-Length Minimization in Networks", Operations Research, vol. 6, no. 2, (1958), pp. 232.

[80] J. A. Muckstadt and A. Sapra, "Principles of Inventory Management: When You Are Down to Four", Order More, Springer, Ed., vol. 1, (2009).

[81] H. Müller-Merbach, "A Five Facets Frame for the Design of Heuristics", European Journal of Operational Research, vol. 17, (1984), pp. 313.

[82] H. Müller-Merbach, "Heuristics and their Design: a Survey", European Journal of Operational Research, vol. 8 , no. $1,(\mathbf{1 9 8 1})$, pp. 1.

[83] K. Neumann and M. Morlock, Operations Research, Carl Hanser, Ed., vol. 2, (2004).

[84] J. B. Orlin, N. Halman, D. Klabjan, M. Mostagir and D. Simchi-Levi, "A Fully Polynomial Time Approximation Scheme for Single-Item Stochastic Lot-Sizing Problems with Discrete Demand", MIT Sloan Research Paper No. 4582-06, (2006).

[85] S. H. Owen and M. S. Daskin, "Strategic Facility Location: a Review", European Journal of Operational Research, vol. 111, (1998), pp. 423.

[86] E. Naddor, "Optimal and Heuristic Decisions in Single- and Multi-Item Inventory Systems", Management Science, vol. 21, no. 11, (1975), pp. 1234.

[87] G. F. Newell, "Scheduling, Location, Transportation, and Continuum Mechanics: Some Simple Approximations to Optimization Problems", Applied Mathematics, vol. 3, no. 25, (1973).

[88] S. K. Norman, D. F. Rogers and M. S. Levy, "Error Bound Comparisons for Aggregation/ Disaggregation Techniques Applied to the Transportation Problem", Computers \& Operations Research, vol. 26, (1999), pp. 1003.

[89] M. O'Kelly, D. Skorin-Kapov and J. Skorin-Kapov, "Lower Bounds for the Hub Location Problem", Management Science, vol. 41, no. 4, (1995), pp. 713.

[90] D. Pisinger, "Heuristics for the Container Loading Problem", European Journal of Operational Research, vol. 141, no. 2, (2002), pp. 382.

[91] D. F. Rogers, R. D. Plante, R. T. Wong and J. R. Evans, "Aggregation and Disaggregation Techniques and Methodology in Optimization”, Operations Research, vol. 39, no. 4, (1991), pp. 553.

[92] J. K. Sankaran, "On Solving Large Instances of the Capacitated Facility Location Problem", European Journal of Operations Research, vol. 178, no. 3, (2007), pp. 663.

[93] M. Savelsbergh and J. Song, "Inventory Routing with Continuous Moves", Computers \& Operations Research, vol. 34, no. 6, (2007), pp. 1744.

[94] A. Scholl, "Robuste Planung und Optimierung", 1. Aufl.; Physica. (2001).

[95] G. Schrimpf, J. Schneider, H. Stamm-Wilbrandt and G. Dueck, "Record Breaking Optimization Results Using the Ruin and Recreate Principle”, Journal of Computational Physics, vol. 159, no. 139, (2000).

[96] H. Shachnai and T. Tamir, "Handbook of Approximation Algorithms and Metaheuristics", Edited T. F. Gonzalez, CRC Press, Ch. "Polynomial-Time Approximation Schemes, in Handbook of Approximation Algorithms and Metaheuristics", (2007). 
[97] C. M. Shetty and R. W. Taylor, "Solving Large-Scale Linear Programs by Aggregation", Computational Operations Research, vol. 14, no. 5, (1987), pp. 385.

[98] E. A. Silver, "An Overview of Heuristic Solution Methods", The Journal of the Operational Research Society, vol. 55, no. 9, (2004), pp. 936.

[99] E. A. Silver, R. Victor, V. Vidal and D. de Werra, “A Tutorial on Heuristic Methods”, European Journal of Operational Research, vol. 5, no. 3, (1980), pp. 153.

[100]H. A. Simon, "The Sciences of the Artificial", The MIT Press, Ed., vol. 3, (1996).

[101]D. Skorin-Kapov, J. Skorin-Kapov and M. O'Kelly, "Tight Linear Programming Relaxations of Uncapacitated p-Hub Median Problems”, European Journal of Operational Research, vol. 94, (1996), pp. 582.

[102]L. V. Snyder, "Facility Location under Uncertainty: a Review”, IIE Transactions, vol. 38, (2006), pp. 537.

[103]R. Sridharan, "The Capacitated Plant Location Problem", European Journal of Operational Research, vol. 87, (1995), pp. 203.

[104]H. Stachowiak, “Allgemeine Modelltheorie”, Springer, Ed. 1, (1973).

[105]A. Suzuki and Z. Drezner, "The p-Center Location Problem in an Area”, Location Science, vol. 4, no. 1/2, (1996), pp. 69.

[106]L. A. Tavasszy, "Freight Modeling - an Overview of International Experiences", Transportation Research Board Conference Proceedings, vol. 40, no. 47, (2006).

[107]A. Töllner, T. Jungmann, M. Bücker and T. Brutscheck, "Das ist gar kein Modell!", Unterschiedliche Modelle und Modellierungen in Betriebswirtschaftslehre und Ingenieurwissenschaften, Edited G. Bandow, H. G. Holzmüller, Gabler, ch. "Modelle und Modellierung: Terminologie, Funktionen und Nutzung", (2010).

[108]R. Vahrenkamp and D. C. Mattfeld, "Logistiknetzwerke: Modelle für Standortwahl und Tourenplanung", Springer, Ed. 1, (2007).

[109]A. Vince, "A Framework for the Greedy Algorithm", Discrete Applied Mathematics, vol. 121, no. 1-3, (2002), pp. 247.

[110]C. Wagenknecht, “Algorithmen und Komplexität”, Carl Hanser, Ed. 1, (2003).

[111]B. Werners, "Grundlagen des Operations Research", Springer, Ed. 2, (2008).

[112]L. A. Wolsey, "Progress with single-item lot sizing", European Journal of Operational Research, vol. 86, (1995), pp. 395.

[113]S. H. Zanakis, J. R. Evans and A. A. Vazacopoulos, "Heuristic Methods and Applications: a Categorized Survey”, European Journal of Operational Research, vol. 43, no. 1, (1989), pp. 88.

\section{Authors}

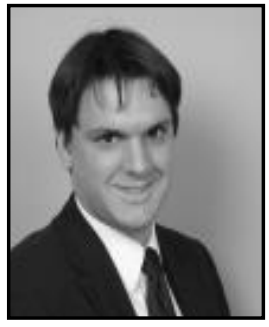

Jun.-Prof. Dr. Hanno Friedrich, studied Industrial Engineering at the KIT. Afterwards he worked for six years at McKinsey \& Company. In 2010 he finished his PHD at the KIT and received a call for a junior professorship in the area of commercial transport at the TU Darmstadt in 2011. Research topics at his chair are freight transport demand modelling, transport economics, risk management and food logistics.

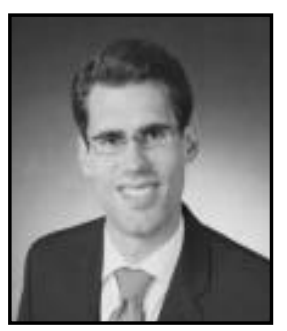

Dipl.-Wi.-Ing. Jonathan Gumpp, studied Business Engineering at the KIT and currently works at the TU Darmstadt. 
International Journal of Transportation Vol.2, No.1 (2014) 